\title{
IMPOSTO PREDIAL E TERRITORIAL URBANO: ALÍQUOTAS PROGRESSIVAS E POLÍTICA URBANA
}

\section{BRAZILIAN URBAN PROPERTY TAX (IPTU): PROGRESSIVE TAX AND URBAN POLICY}

Ana Maria Isar dos Santos Gomes ${ }^{1}$

Resumo: O artigo discute a utilização de alíquotas progressivas do Imposto Predial e Territorial Urbano (IPTU) com função fiscal e extrafiscal. A pesquisa de natureza documental e bibliográfica tem por objetivo demonstrar, por meio do histórico do desenvolvimento das cidades brasileiras, a necessidade de utilização do IPTU com função extrafiscal para combater disfunções urbanísticas relacionadas à especulação imobiliária. Ao final, traz uma coletânea das pesquisas acadêmicas que permitem identificar problemas já enfrentados na implantação do IPTU progressivo no tempo em seis municípios brasileiros (Assis-SP, Santo André-SP, Maringá-PR, São Paulo-SP, Curitiba-PR e Palmas-TO).

Palavras-Chave: IPTU Progressivo. Política Urbana. Extrafiscalidade. Vazios Urbanos. Imóveis Vagos. Especulação Imobiliária.

Abstract: The article discusses Brazilian Urban Land and Territorial Tax (IPTU) progressive rates. The higher taxes can have fiscal or extrafiscal purpose. The documentary and bibliographic research addresses financial aspects of IPTU (fiscal purpose) and also demonstrates, by a brief history of the development of Brazilian cities, that IPTU can be applied to avoid the consequences of dysfunctional urbanization, especially those related to speculative Housing Market (extrafiscal purpose). A collection of academic researches allows identifying problems in the implementation of progressive rates of IPTU in six Brazilian municipalities (Assis-SP, Santo André-SP, Maringá-PR, São Paulo-SP, Curitiba-PR and Palmas -TO).

Key Words: Brazilian Urban Property Tax (IPTU). Urban Policy. Progressive Tax. Urban Voids. Vacant Properties. Speculative Housing Market.

\footnotetext{
${ }^{1}$ Doutoranda em Direito Público pelo Programa de Pós-Graduação da Faculdade de Direito da PUC Minas, Mestre em Geografia (Gestão Ambiental e Territorial) pela Universidade de Brasília UnB e Procuradora do Distrito Federal. Membro de Grupo de Pesquisa do Núcleo de Estudos Urbanos e Regionais da UnB vinculado ao CNPQ. E-mail: anaisar@uol.com.br.

Rev. de Direito Urbanístico, Cidade e Alteridade | e-ISSN: 2525-989X | Goiânia | v. 5 | n. 1 | p. 62-82| Jan/Jun. 2019
} 


\section{INTRODUÇÃO}

Junho de 2017. Um incêndio na Grenfell Tower, edifício de habitações populares no bairro de North Kensington, em Londres, choca o Reino Unido. Um mês antes do início das investigações para apurar as causas da tragédia, Jeremy Corbyn, importante membro do Partido Trabalhista inglês, em carta aberta dirigida à primeira-ministra Theresa May, levanta questionamentos quanto à política de habitação nacional conduzida no Reino Unido (ELGOT, 2017).

Maio de 2018. O edifício Wilton Paes de Almeida, no Largo do Paissandu, região central de São Paulo, desaba após pegar fogo, deixando sete mortos. A construção abrigava cerca de 290 famílias que ocupavam o imóvel de forma irregular (QUIERATI, 2018).

O que as tragédias acima têm em comum? Elas reacendem o debate sobre a crise habitacional nas metrópoles. Em ambos os casos, o grande número de desabrigados convive com uma alta quantidade de imóveis desocupados ${ }^{2}$.

No Reino Unido, desde 2013 as autoridades locais podem sobretaxar o council tax imposto anual semelhante ao Imposto Predial e Territorial Urbano (IPTU) cobrado no Brasil para desestimular a manutenção de imóveis desocupados ${ }^{3}$. Em Kensington e Chelsea, por exemplo, proprietários de imóveis desocupados por dois anos ou mais pagam um adicional de $100 \%$ do valor do council tax ${ }^{4}$.

A Constituição Federal brasileira prevê a cobrança de IPTU com alíquotas progressivas no tempo (art. 182, § $4^{\circ}$, inciso II) nos casos em que o proprietário do imóvel ocioso não promove seu adequado aproveitamento. Contudo, os governos municipais relutam em aplicar o dispositivo constitucional e, quando o fazem, não conseguem alcançar os

\footnotetext{
${ }^{2}$ No caso de Londres, o número de desabrigados cresce ano após ano desde o desmonte dos programas habitacionais no governo de Margaret Thatcher, e chega, hoje, a cerca de 35 mil pessoas, conforme reportagem do jornal inglês The Guardian de 31 de dezembro de 2018 (LONDON, 2018). A tragédia da Torre Grefell levou a Prefeitura da cidade a se empenhar em encontrar imóveis para alojar as famílias vitimadas pelo incêndio. Descobriu-se que havia, só na região do incêndio, quase 1.700 moradias vazias, conforme reportagem publicada no The Guardian em 02 de agosto de 2017 (WALKER; PEGG, 2017). Em São Paulo, milhares de cidadãos moram nas ruas enquanto o número de imóveis vagos é elevadíssimo, conforme registra o último relatório da Fundação João Pinheiro (2018).

${ }^{3}$ Informação obtida no site do Governo do Reino Unido (UNITED KINGDOM GOVERNMENT. MINISTRY OF HOUSING, COMMUNITIES AND LOCAL GOVERNMENT, 2019).

${ }^{4}$ Informação obtida no site da Administração de Kensington e Chelsea (THE ROYAL BOROUGH OF KENSINGTON AND CHELSEA, 2019).
} 
objetivos pretendidos. Quais são os empecilhos para a utilização do IPTU progressivo no tempo?

Este artigo apresenta, por meio de pesquisa documental e bibliográfica, um panorama das possibilidades de utilização do IPTU como instrumento de política tributária e urbana. A primeira seção aborda a função fiscal do IPTU, que inclui, além da arrecadação para custear as despesas do Estado, a redistribuição de renda por meio da instituição de alíquotas progressivas conforme o valor do imóvel, localização e uso. Na segunda seção é analisada a função extrafiscal do IPTU e a sua importância para evitar o crescimento disfuncional das cidades e a especulação imobiliária. A terceira seção traz um apanhado das pesquisas acadêmicas sobre experiências nacionais de cobrança do IPTU com função extrafiscal. Conclui-se que a eficiência na utilização do IPTU progressivo no tempo depende da escolha estratégica das áreas sujeitas à aplicação do instrumento, de forma a: (i) combater os vazios urbanos; (ii) promover melhor aproveitamento dos imóveis vagos, com aumento na oferta habitacional para a população de baixa renda; (iii) garantir que sua utilização atenda à função social da propriedade e não aos interesses exclusivos do capital.

\section{O IPTU COM FUNÇÃO FISCAL: ASPECTOS FINANCEIROS DA TRIBUTAÇÃO E REFLEXOS NA REDISTRIBUIÇÃO DE RENDA}

Os estudos de Direito Tributário produzidos no país costumam ignorar as finanças públicas, que, em última análise, determinam a cobrança dos impostos analisados, afirma Godoi (2017). Esse desalinhamento entre as teorias jurídicas e a realidade econômica e política do país tem levado, segundo o autor, a afirmações segundo as quais "determinada tributação é justa ou injusta independentemente da maneira pela qual o uso dos recursos arrecadados irá afetar as pessoas que se submeteram à tributação" (GODOI, 2017, p. 9) ${ }^{5}$. O autor ressalta que essa postura não coaduna com a nossa Constituição Federal, marcadamente influenciada pelas constituições europeias, especialmente a portuguesa e espanhola, nas quais

\footnotetext{
${ }^{5} \mathrm{O}$ autor ressalta que essa postura não coaduna com a nossa Constituição Federal, marcadamente influenciada pelas constituições europeias, especialmente a portuguesa e espanhola, nas quais o fundamento do dever de pagar impostos tem por base a solidariedade social. A ideia de solidariedade social permeia o texto constitucional e aparece, especialmente, no artigo $3^{\circ}$, inciso I, da Constituição Federal, segundo o qual é um dos objetivos fundamentais da República Federativa do Brasil "construir uma sociedade livre, justa e solidária".
}

Rev. de Direito Urbanístico, Cidade e Alteridade | e-ISSN: 2525-989X | Goiânia | v. 5 | n. 1 | p. 62-82| Jan/Jun. 2019 
o fundamento do dever de pagar impostos tem por base a solidariedade social ${ }^{6}$. Daí porque uma análise acerca da função do IPTU progressivo na política urbana não prescinde de uma passagem, ainda que breve, pelas finanças públicas, de forma a correlacionar a receita a ser auferida com esse tributo com as despesas que ele financia.

Do ponto de vista da receita pública, a arrecadação do IPTU não é vinculada à política urbana, mas integra a arrecadação geral do município, destinada, entre outros fins, ao custeio dos diversos programas de política pública. Dessa forma, é importante considerar em que medida essas políticas públicas têm se orientado pelo critério de justiça social, isto é, têm funcionado como instrumento de redistribuição de renda. Em outras palavras: é fundamental compreender em que medida a arrecadação do IPTU obedece ao princípio da progressividade de forma a distribuir solidariamente os ônus tributários de uma sociedade extremamente injusta do ponto de vista social.

O IPTU tem algumas vantagens arrecadatórias sobre os demais impostos. Em primeiro lugar, sua arrecadação oscila pouco, já que não depende diretamente do desempenho da economia. Além disso, como a sua base de cálculo é um bem imóvel, a receita é arrecadada sempre pelo mesmo ente federado, não estando sujeita, assim, à guerra fiscal, como acontece com o Imposto sobre Circulação de Mercadorias e Serviços (ICMS) e o Imposto sobre Serviços (ISS). Acresce-se a isso o fato de que é um imposto direto e, portanto, de mais fácil arrecadação. Contudo, esse imposto não é a principal fonte de arrecadação municipal, conforme constatou Carvalho Júnior (2017) em abrangente estudo sobre os aspectos redistributivos do IPTU: a participação do IPTU na receita nacional tem se mantido, desde a década de 2000 , entre $0,4 \%$ e $0,5 \%$ do PIB, embora vários estudos indiquem que esse índice pode subir até $1 \%$ do PIB.

Com relação ao papel deste imposto nos cofres municipais, Carvalho Júnior (2009, 2017) demonstra que a participação do IPTU vem caindo e representou, em 2015, apenas 5\% das receitas municipais no Brasil ${ }^{7}$ - índice muito baixo se comparado com países como Nova Zelândia, Austrália, França, Israel e Canadá, onde os impostos sobre propriedade imobiliária

\footnotetext{
${ }^{6} \mathrm{~A}$ ideia de solidariedade social permeia o texto constitucional e aparece, especialmente, no artigo $3^{\circ}$, inciso I, da Constituição Federal, segundo o qual é um dos objetivos fundamentais da República Federativa do Brasil "construir uma sociedade livre, justa e solidária"

${ }^{7}$ Conforme Carvalho Júnior, esse índice não reflete a realidade de cada município, pois a arrecadação do IPTU é bastante heterogênea no país, variando regionalmente e conforme o tamanho do município: "Em 2016, apenas o Município de São Paulo concentrou 24\% de toda a arrecadação nacional do IPTU e mais outros 13 municípios concentraram 50\% da arrecadação nacional. Em $80 \%$ dos municípios brasileiros, o indicador de arrecadação do IPTU pelo PIB está abaixo de 0,25\%; e, como proporção das. receitas correntes, está abaixo de 2\%." (CARVALHO JÚNIOR, 2017, p. 5).
} 
representaram mais de $25 \%$ das receitas dos entes locais no período de 2002 a 2005. Como as alíquotas praticadas aqui não são muito diferentes daquelas praticadas naqueles países, o autor assinala que a baixa arrecadação pode ter como causa a ineficiência administrativa e a concessão de isenções e reduções do imposto (CARVALHO JÚNIOR, 2017). Outro motivo a ser considerado é o fato de que muitos dos moradores das cidades brasileiras ocupam imóveis não regularizados e, portanto, não registrados no cadastro imobiliário dos municípios.

Quanto à distribuição dos ônus tributários, embora a pesquisa realizada pelo autor em 2009 tenha coberto apenas o período $2002-2003^{8}$, revelou que o peso das famílias mais ricas na arrecadação é proporcionalmente maior ${ }^{9}$. Contudo, ao restringir a análise apenas ao universo de pagantes, Carvalho Júnior mostra que a cobrança desse imposto foi caracterizada por alta regressividade, de forma que os contribuintes mais pobres sofreram uma tributação muito mais significativa, proporcionalmente ${ }^{10}$. O autor conclui que "uma ampla política de isenção de IPTU aliada à má qualidade administrativa e avaliatória acabam isentando famílias de renda média e alta do pagamento desse imposto" e alerta para a necessidade de se atentar aos "aspectos distributivos do IPTU e não apenas ao mero aumento ou progressão das alíquotas” (CARVALHO JÚNIOR, 2009, p. 5).

O estudo de Carvalho Júnior também aborda a aplicação de alíquotas progressivas do IPTU com função fiscal. Embora os dados coletados sejam de 2002-2003, época em que a emenda constitucional 29/2000 - que autorizou a cobrança de alíquotas progressivas em razão do valor, localização e uso do imóvel ( $\mathrm{CF}$, artigo $\left.156, \S 1^{\circ}\right)$ - ainda era recente, a pesquisa constatou que vários municípios já aplicavam alíquotas progressivas conforme a capacidade contributiva. A pesquisa demonstra que, em alguns deles, como Curitiba, São Paulo e Belo Horizonte, "a carga tributária foi regressiva a partir do último pentil de valores de imóveis" (CARVALHO JÚNIOR, 2009, p. 28). O autor chama a atenção para a possibilidade de que as

\footnotetext{
${ }^{8}$ Os dados utilizados por Carvalho Júnior foram extraídos da Pesquisa de Orçamentos Familiares (POF) de 2002-2003 e da Pesquisa Nacional por Amostra de Domicílios (Pnad) de 2003, ambas do Instituto Brasileiro de Geografia e Estatística (IBGE).

${ }^{9}$ De acordo com o estudo, o percentual de imóveis que responderam pelo pagamento do tributo aumentou progressivamente conforme aumentava a despesa familiar, de forma que, na faixa de famílias $10 \%$ mais pobre, ele foi de pouco mais de $10 \%$, enquanto na faixa de famílias $10 \%$ mais rica o percentual foi equivalente a cerca de 70\%. O baixo percentual de imóveis que recolhem IPTU entre as camadas mais pobres da população pode ser explicado pelas políticas de isenção tributária, mas também pelo grande número de moradores em assentamentos informais, cujos imóveis não constam do cadastro imobiliário fiscal dos municípios (CARVALHO JÚNIOR, 2009).

${ }^{10}$ Segundo o autor, "a participação do IPTU na despesa de todas as famílias é em torno de 0,5\% no segmento dos $20 \%$ mais pobres, em torno de $1,8 \%$ nos $10 \%$ mais ricos e em torno de $1,1 \%$ nos demais estratos intermediários, o que demonstra certa progressividade da carga tributária. Porém, considerando-se a distribuição somente no universo de pagantes, a situação se inverte: a participação média é de cerca de $4 \%$ da despesa das famílias pagantes entre os $50 \%$ mais pobres e de $2,9 \%$ entre os $50 \%$ mais ricos." (CARVALHO JÚNIOR, 2009, p. 22)
} 
avaliações imobiliárias sejam tão regressivas ${ }^{11}$ nas cidades acima, que o efeito progressivo das alíquotas tenha sido anulado. Outro possível motivo para a falta de efetividade da norma é a forma como as alíquotas são calibradas. Em alguns casos, elas podem não refletir a real distribuição dos valores venais dos imóveis existentes no município, de forma que as alíquotas maiores acabam recaindo sobre um número muito baixo de imóveis ${ }^{12}$.

Deve-se lembrar que a redistribuição de renda não se dá unicamente por uma política justa de arrecadação, mas também pela transferência de recursos dos cofres públicos para o mercado, por meio das despesas públicas (GODOI, 2017). Entre as despesas públicas estão os gastos com as políticas sociais, especialmente as políticas de moradia, saneamento e transporte público. Assim, vale trazer alguns dados sobre os recursos de que dispõem os municípios para financiar tais políticas.

A Constituição de 1988 promoveu a descentralização fiscal, na medida em que conferiu aos municípios autonomia orçamentária para desenvolverem suas próprias políticas sociais (com exceção das políticas de saúde e educação), entre as quais a política urbana. Contudo, essa autonomia não foi acompanhada de um sistema de distribuição de receitas entre os entes da federação que garantisse autossuficiência financeira aos municípios, de sorte que eles dependem de repasse de recursos por parte da União ${ }^{13}$ (ARRETCHE, 2004).

Se a autonomia municipal permite, por um lado, que os municípios inovem na gestão de suas políticas públicas, a exemplo das experiências de orçamento participativo levadas a cabo por muitos deles a partir da década de 1980, também enfraquece a coordenação da

11 A regressividade na avaliação de imóveis é assim explicada, por Carvalho Júnior: "De Cesare (2004) e Varsano (1977) afirmam que os imóveis de valores mais baixos de mercado têm maior probabilidade de sofrerem erros no processo de avaliação imobiliária para fins tributários. Isso é bastante intuitivo, porque os erros avaliatórios costumam ter valores discretos, afetando mais que proporcionalmente os imóveis de valores mais baixos. Por exemplo, é mais provável que um imóvel de valor de mercado de R $\$ 10$ mil seja avaliado em R \$ 15 mil (uma sobreavaliação de 50\%) do que um imóvel de R \$ 200 mil ser sobreavaliado em R \$ 300 mil.” (CARVALHO JÚNIOR, 2009, p. 18)

${ }^{12} \mathrm{O}$ autor cita como exemplo o município de Belo Horizonte, “onde a alíquota maior só incide sobre imóveis de valor venal acima de R 500 mil, o que seria menos de $1 \%$ das residências da cidade, se esses valores venais fossem iguais aos de mercado" (CARVALHO JÚNIOR, 2009, p. 28).

${ }^{13}$ No caso da política de habitação e saneamento, a principal fonte de financiamento provém de empréstimos da União aos municípios por meio do Fundo de Garantia de Tempo de Serviço (FGTS), cuja receita é vinculada (ARRETCHE, 2004). Além disso, os municípios contam com transferências obrigatórias do Fundo de Participação dos Municípios, não vinculadas à política urbana. Além desses repasses obrigatórios, existem as transferências voluntárias por parte da União, "negociadas caso a caso", por meio de convênios que obedecem a critérios estabelecidos em processos de seleção de projetos (orçamento programável) ou de emendas parlamentares (ROLNIK; KLINK, 2011, p. 106). Esse modelo fiscal é conhecido na literatura, segundo Rolnik e Klink (2011), como descentralização tutelada. A área de política urbana, ao lado da saúde, é a que mais recebe emendas por parte dos congressistas: tais emendas são "carimbadas", isto é, vinculadas ao município onde serão aplicados os recursos, o que acaba servindo como moeda de troca eleitoral. (ROLNIK; KLINK, 2011, p. 106) 
política urbana em nível nacional. A criação do Ministério das Cidades, em 2003, foi importante, sob esse aspecto, porque permitiu concentrar esforços na solução dos grandes problemas urbanos nacionais, por meio de políticas setoriais (políticas nacionais de habitação, mobilidade, saneamento público e regularização fundiária).

Costa, Gomes e Adriano (2017), ao analisarem a política urbana conduzida no país de 2003 até 2016, dividem esse período em duas fases: a primeira, que dura de 2003 até 2007, ano em que foi lançado o Plano de Aceleração do Crescimento (PAC), e a segunda, que vai de 2007 a $2016^{14}$. A primeira fase, segundo os autores, caracterizou-se pela participação da sociedade em canais criados pelo Governo para promover a gestão democrática das cidades. A segunda fase é caracterizada pelo aumento do protagonismo dos atores políticos ligados ao capital, com reflexos na condução da política urbana ${ }^{15}$.

A atuação do capital na produção do espaço urbano se dá não só pela via do mercado, mas também pela via estatal, na medida em que a política urbana é resultado de uma relação de forças entre os atores políticos que participam de sua produção, interferindo e influenciando o processo de tomada de decisões. Nesse sentido, convém lembrar que a prevalência constante dos interesses do capital sobre os interesses da comunidade na condução da política urbana - com resultados danosos ao desenvolvimento das cidades - já foi diagnosticado em inúmeros estudos urbanísticos ${ }^{16}$.

Do ponto de vista do mercado, um dos maiores entraves para o desenvolvimento de uma política habitacional eficiente é a especulação imobiliária derivada "da mera retenção ociosa/inativa de terrenos". Conforme Morales-Schechinger (s.d.), tal especulação é extremamente nociva, pois promove uma escassez artificial no mercado imobiliário, que inflaciona sobremaneira o preço da propriedade urbana e prejudica o acesso das camadas mais pobres da população à moradia. Esse problema é apontado por muitos como o nó górdio da questão habitacional. Contudo, ao invés de uma solução criativa e rápida, como na lendária estória de Alexandre, o Grande, sua dissolução requer ações mais complexas.

\footnotetext{
${ }^{14}$ Para uma análise completa da política urbana desenvolvida no país no período 2003-2016, ver Costa, Gomes e Adriano (2017).

15 O PAC Habitação, lançado em 2007, e o Programa Minha Casa Minha Vida, em 2009, foram bastante criticados por urbanistas, embora não se possa menosprezar os resultados quantitativos de tais programas: em sete anos eles representaram investimentos de cerca de R \$ 295 bilhões, contratação de mais de 4 milhões e duzentas mil unidades habitacionais e aproximadamente 10, 5 milhões de pessoas beneficiadas (MOREIRA; SILVEIRA; EUCLYDES, 2017). Como seu objetivo era estimular a economia por meio de uma ação anticíclica de incentivo da produção e geração de empregos, os programas priorizaram a construção de unidades habitacionais em lugares afastados do centro, ao invés de investirem na regularização de assentamentos urbanos informais, o que acentuou o problema de mobilidade urbana nas cidades, com reflexos na elevação dos preços das passagens e do tempo gasto no transporte para o trabalho.

${ }^{16}$ A respeito, ver Rolnik (2015), Maricato (2011) e Fix (2007).
} 


\section{A FUNÇÃO EXTRAFISCAL DO IPTU}

Embora Adam Smith já refletisse, em sua célebre obra A Riqueza das Nações, acerca das possibilidades de utilização do imposto para induzir ou desestimular comportamentos dos proprietários de terras ${ }^{17}$, as origens da extrafiscalidade costumam ser traçadas pela doutrina a partir de Adolph Wagner, economista alemão que se notabilizou pela defesa do socialismo acadêmico na era de Bismarck. Para Adamy (2018), Wagner demonstrou, em uma época em que a Europa vivia uma situação de extrema desigualdade social, que os impostos poderiam ser utilizados não só para financiar as atividades do Estado, mas também para promover uma melhor distribuição de renda.

Hodiernamente, o termo extrafiscalidade é utilizado pela doutrina para se referir às hipóteses em que a atividade tributária tem por objetivo principal não o custeio das despesas do Estado, mas a sua intervenção no domínio econômico ${ }^{18}$. Tal intervenção pode se dar por meio de uma atividade macroeconômica ${ }^{19}$, como, por exemplo, implementação de políticas públicas de transferência de renda, estímulo à produção ou incentivo a setores da economia. Outra forma de intervir no domínio econômico é por meio da atividade microeconômica, isto é, pela indução de comportamentos individuais e desestímulo de condutas prejudiciais à coletividade. Ao comentar esse tipo de intervenção, Marins e Teodorovicz (2011, p. 173) afirmam que, "sendo o tributo um instrumento de natureza financeira, interferindo no patrimônio, na atividade econômica, na vida social, cultural, político e ambiental, torna-se hábil instrumento para a modelagem de comportamentos humanos”.

O IPTU é um dos poucos impostos com funções fiscal e extrafiscal previstas expressamente na Constituição. Sua função fiscal - diretamente ligada à arrecadação tributária, inclusive por meio de alíquotas diferenciadas conforme a capacidade contributiva dos cidadãos (justa distribuição do ônus tributário pela sociedade) - está prevista no artigo 156, inciso I, da Constituição Federal. A função extrafiscal, por sua vez, é tratada no artigo

17 Adam Smith considerava, por exemplo, a possibilidade de abatimento moderado do imposto para os proprietários que se dispusessem a produzir eles próprios em parte das suas terras. Sugeria, também, o aumento no valor dos impostos cobrados de arrendadores que cobrassem luvas na renovação do contrato ou obrigassem os arrendatários a um determinado modo de cultivo ou ao pagamento da renda em gêneros alimentícios ao invés de dinheiro (SMITH, 1996).

${ }^{18}$ Nesse sentido, ver Machado (2005), Torres (2006) e Marins e Teodorovicz (2011).

${ }_{19}$ Baleeiro (2001), por exemplo, entende que a teoria keynesiana pode ser tomada como um exemplo de extrafiscalidade, na medida em que propõe um conjunto de medidas financeiras (relacionadas a despesas públicas, impostos, empréstimos etc.) adotadas para transformar a estrutura econômica do Estado. 
$182, \S 4^{\circ}$, inciso II, cujo objetivo é induzir os proprietários de imóveis subaproveitados a promoverem o parcelamento, edificação e/ou utilização adequada de seus imóveis.

Um dado desperta a atenção quando se analisa o mercado imobiliário brasileiro: de acordo com o último levantamento realizado pela Fundação João Pinheiro (2018), o número de imóveis vagos no país é maior do que o déficit habitacional ${ }^{20}$. Esse dado, associado ao fato de que existe concentração no usufruto dos bens imobiliários residênciais ${ }^{21}$, leva à constatação de que o mercado imobiliário urbano, no Brasil, é altamente especulativo.

Para compreender como funciona o mercado imobiliário brasileiro, é importante lembrar que o país sofreu um rápido processo de urbanização depois da década de 1930, intensificado a partir da década de 1960 (BRITO, 2006). O modelo de desenvolvimento adotado pelo país levou ao crescimento econômico acelerado (especialmente entre as décadas de 1940 e 1970) e ao aprofundamento da desigualdade social, com consequente aumento no déficit habitacional. Ao mesmo tempo, o sistema financeiro nacional contava com poucas opções para investimento do capital até a década de 1970, de forma que uma "parcela significativa das poupanças foi investida no setor imobiliário, o que resultou em fortes processos de especulação com a terra” (CARDOSO, 2007. p. 222).

Outra circunstância que contribuiu para a especulação imobiliária foi o surgimento de um mercado informal de terras. A criação do Banco Nacional de Habitação (BNH), em 1964, representou a primeira iniciativa do governo na tentativa de reverter o déficit habitacional nacional. Contudo, os programas habitacionais se limitavam a viabilizar acesso ao crédito, sem qualquer preocupação com o planejamento urbanístico, o que levou à proliferação de aglomerações de prédios nas periferias, ao redor dos quais se consolidaram assentamentos informais (MARGUTI, 2018).

Tais assentamentos eram, na verdade, loteamentos constituídos à revelia das leis, e, portanto, não cadastrados nos órgãos públicos. Assim, grande quantidade de imóveis - em áreas desprovidas de infraestrutura urbana - passou a ser comercializada à revelia dos

\footnotetext{
${ }^{20} \mathrm{O}$ último levantamento realizado pela Fundação João Pinheiro, referente ao ano de 2015, revela que o país possuía 6,3 milhões de imóveis urbanos disponíveis (em condições de serem ocupados/em construção ou reforma). Considerando-se que o déficit habitacional em área urbana, no mesmo ano, foi de 5,6 milhões de moradias, percebe-se que, à época da pesquisa, o número de domicílios vagos nas cidades era maior (se considerarmos o déficit habitacional geral) do que o déficit habitacional. Apenas para se ter uma ideia dessa proporção por região, a pesquisa mostra que a região Sudeste tinha um déficit de 2,5 milhões de unidades habitacionais nas cidades e 2,7 milhões de domicílios vagos, incluindo aqueles em condições de serem ocupados e em construção, sem contar os domicílios em ruínas e aqueles de uso ocasional (FUNDAÇÃO JOÃO PINHEIRO, 2018).

${ }^{21}$ Conforme pesquisa de Carvalho Júnior (2009), utilizando dados de 2002-2003, apenas 5\% das famílias usufruíam, à época, de 32,2\% do estoque de imóveis residenciais existente no país.
} 
registros públicos. A situação se agravou na década seguinte, com a adoção do modelo neoliberal e abandono do planejamento urbano pelo Estado.

Conforme Smolka (2003), o mercado informal gera mais lucro, em geral, do que o formal, já que os preços dos imóveis costumam embutir a valorização futura decorrente dos investimentos do Estado em infraestrutura. Com isso, muitos dos proprietários de imóveis regulares - que podem se dar ao luxo de aguardar o melhor momento para comercializar seus imóveis - deixam de oferecê-los no mercado, o que leva à retração do mercado formal e favorece a especulação imobiliária.

Quando a especulação imobiliária tem por objeto imóveis não edificados, promove o que se denomina de vazios urbanos. Conforme Cardoso (2012), os vazios urbanos começaram a ser percebidos nas metrópoles brasileiras na década de 1970, quando estudos econômicos mostraram que o crescimento dessas cidades a partir das periferias deixava grandes porções de terras vazias nas regiões centrais. Tais imóveis eram mantidos fora do mercado, à espera de valorização. Do ponto de vista urbanístico, esse processo mostrou-se extremamente disfuncional, pois: (i) elevou artificialmente a demanda e, consequentemente, o preço dos imóveis; (ii) exigiu a instalação de infraestrutura nas áreas periféricas, efetivamente ocupadas; (iii) levou à valorização de áreas privadas, em razão de investimento do Estado, sem a correspondente recuperação da mais-valia por parte do Poder Público (CARDOSO, 2012).

A partir da década de 1980, o mercado passou a ocupar os vazios urbanos deixados em algumas metrópoles com empreendimentos de grande porte, em uma estratégia de recaracterização e sobrevalorização de bairros inteiros. $O$ deslocamento das atividades comerciais, de serviços e residenciais (classe média e alta) para novas centralidades levou ao abandono e degradação de prédios inteiros (CARDOSO, 2012). Embora não ofereçam moradia adequada, muitos desses prédios passaram a ser ocupados, especialmente a partir da década de 1990, por populações de baixa renda, em um processo denominado pelos urbanistas de "encortiçamento" 22 . Cardoso (2012, p. 5) ressalta que algumas dessas ocupações chegaram a ser regularizadas durante a gestão de Luíza Erundina, quando foram desenvolvidos projetos "de melhoria significativa das condições de habitabilidade dos prédios". Nesse sentido, é importante ter em mente que edifícios abandonados representam um estoque de habitações que pode ser readequado pelo próprio Estado para garantia do direito à moradia.

\footnotetext{
${ }^{22}$ Levantamento realizado depois do incêndio no Edifício Wilton Paes de Almeida mostrou que, só na região central da cidade de São Paulo, havia 70 edifícios públicos e privados ocupados por 4.000 famílias (LISBÔA, 2018).
} 
Esse breve retrato do mercado imobiliário nacional revela que a solução do problema habitacional passa pelo combate à especulação, não só como forma de evitar a hipervalorização dos imóveis urbanos, mas também para dar adequado aproveitamento a imóveis ociosos (edificados ou não) nas regiões já dotadas de infraestrutura básica (água, esgoto, saneamento, energia elétrica). Em outras palavras: trata-se de conferir à propriedade urbana sua função social (artigos $5^{\circ}$, inciso XXIII, 170, inciso III, e 182, caput, da Constituição Federal). Entre os instrumentos urbanísticos e tributários de que dispõe o município para tal tarefa está o IPTU progressivo no tempo, regulamentado no Estatuto da Cidade (Lei 10.251/2001, artigo $4^{\circ}$, inciso IV, alínea "a" e artigo $7^{\circ}$ ). Contudo, para que que se alcancem resultados positivos, é necessário, de um lado, uma jurisprudência consentânea com os princípios constitucionais de solidariedade e justiça social, e, de outro, um planejamento estratégico eficiente por parte dos Poderes Legislativo e Executivo.

Com relação à jurisprudência, a progressividade do IPTU no tempo, ao contrário do que ocorreu com a progressividade conforme a capacidade contributiva ${ }^{23}$, não gerou até agora grandes questionamentos judiciais. Isso pode ser explicado pelo fato de que o dispositivo constitucional que autoriza sua cobrança apenas foi regulamentado em 2001, com a edição da Lei 10.257 (Estatuto da Cidade). Além disso, mesmo depois da sua regulamentação, o instrumento não despertou muito interesse dos municípios. Oliveira e Biasotto (2011), ao analisarem os Planos Diretores dos municípios brasileiros, constataram que, embora quase todos tenham incluído em seu texto os instrumentos jurídico-urbanísticos

\footnotetext{
${ }^{23} \mathrm{O}$ artigo 156, que prevê a cobrança de alíquotas diferenciadas em razão da capacidade contributiva, gerou vigorosos embates judiciais, tão logo promulgada a Constituição. Tais embates foram motivados pelo fato de que o seu parágrafo $1^{\circ}$, que previu expressamente a utilização da progressividade do tributo em razão do valor, localização e uso do imóvel, apenas foi introduzido pela emenda constitucional 29/2000. Antes da promulgação da emenda, os Municípios de Belo Horizonte e São Paulo editaram, respectivamente, as leis 5.641/89 e 10.921/90, que instituíam alíquotas progressivas de IPTU em razão de características dos imóveis. No julgamento dos Recursos Extraordinários (RE) 153.771-0/MG e 204.827/SP, o Supremo Tribunal Federal (STF) declarou inconstitucionais as leis municipais, decidindo que a única progressividade admitida para o IPTU seria aquela prevista no artigo $182, \S 4^{\circ}$, inciso II, da Constituição Federal, uma vez que a autorização constitucional para instituir a progressividade conforme a capacidade do contribuinte, prevista no artigo $145, \S 1^{\circ}$, seria limitada aos impostos pessoais. O STF foi novamente chamado a se manifestar sobre o artigo $156, \S 1^{\circ}$, da Constituição Federal, depois da promulgação da emenda 29/2000, quando foram propostas ações por contribuintes que impugnavam leis municipais editadas antes da alteração constitucional. No julgamento do RE 355.046, o plenário da Corte chegou ao entendimento sumulado no verbete 668, segundo o qual "é inconstitucional a lei municipal que tenha estabelecido, antes da emenda constitucional 29/2000, alíquotas progressivas para o IPTU, salvo se destinada a assegurar o cumprimento da função social da propriedade urbana". Em 2012, foi reconhecida a repercussão geral do RE 666.156/RJ, em que se debate a possibilidade de instituição de alíquotas de IPTU distintas para imóveis residenciais, edificados e não edificados, no período anterior à emenda constitucional 29/2000. Considerando-se que o recurso foi retirado de pauta e que houve mudança jurisprudencial acerca da tese de que seria necessária autorização constitucional para instituição de progressividade nos impostos reais, verificada no julgamento do RE 562.045/RS, é esperada a alteração da jurisprudência.
} 
destinados a promover o aproveitamento adequado do imóvel urbano (artigo 182, § $4^{\circ}$, da Constituição), poucos deles regulamentaram tais instrumentos.

Na próxima seção, serão analisadas experiências de alguns municípios que não só regulamentaram o IPTU progressivo no tempo, como também adotaram medidas para sua cobrança.

\section{EXPERIÊNCIAS MUNICIPAIS NA IMPLANTAÇÃO DO IPTU PROGRESSIVO NO TEMPO}

A aferição de quantos e quais são os municípios que utilizam o IPTU com função extrafiscal não é tarefa fácil. Levantamento realizado pelo Ministério da Justiça em 2014 (com grau de incerteza, conforme mencionado no documento) indica que, naquele ano, apenas dois municípios - Maringá (PR) e São Bernardo do Campo (SP) - estavam adotando medidas para iniciar a cobrança do IPTU com função extrafiscal (BRASIL, 2015a).

A dificuldade de se obter dados sobre a cobrança de alíquotas progressivas no tempo é explicada pelo fato de que tais alíquotas incidem sobre a mesma base de cálculo das alíquotas previstas no artigo $156, \S 1^{\circ}$, da Constituição, além de terem os mesmos sujeitos ativo e passivo. Assim, a cobrança é feita de maneira conjunta no lançamento do IPTU e revertida posteriormente, caso o proprietário cumpra a obrigação de parcelar, edificar ou utilizar adequadamente o imóvel no ano seguinte (BRASIL, 2015b).

A despeito dessa dificuldade, um levantamento dos estudos acadêmicos sobre o tema indica que a cobrança de alíquotas progressivas no tempo foi implementada nos municípios de Assis-SP (FLOETER, 2007), Santo André-SP (BRUNO FILHO; DENALDI, 2009), São Paulo-SP e Curitiba-PR (FARIA, 2013), Maringá-PR (BRAJATO, 2015) e Palmas-TO (CRUZ, 2017).

O primeiro município a aplicar o IPTU progressivo no tempo, ainda no período anterior à Constituição de 1988, foi o município de Assis (SP). Conforme Floeter (2007), a implantação de muitos loteamentos na cidade, entre 1970 e 1990, levou à retenção de lotes urbanos para fins especulativos. A solução encontrada pela Prefeitura foi a cobrança de IPTU com alíquotas progressivas dos proprietários de lotes mantidos ociosos por período superior a dois anos. Interessante notar que as leis municipais 1.961/1977 e 2.250/1983, que instituíam as alíquotas progressivas do IPTU, não chegaram a ser apreciadas pelo STF, embora, à época, o posicionamento da Corte fosse pela inconstitucionalidade da cobrança do IPTU progressivo 
(Súmula 589, de 1976). O estudo de Floeter mostra que, embora os resultados tenham sido positivos em um primeiro momento, a descontinuidade administrativa aliada à pressão política do mercado imobiliário local acabou interferindo na aplicação do instrumento. A falta de reajustes da Planta Genérica de Valores dos imóveis municipais acabou por tornar a lei inefetiva, o que levou à perda geral de arrecadação derivada desse imposto.

Santo André tornou-se o primeiro caso notório de utilização do IPTU progressivo no tempo depois da promulgação do Estatuto da Cidade. Bruno Filho e Denaldi (2009) anotam que o objetivo da Prefeitura era utilizar os imóveis ociosos em áreas dotadas de infraestrutura para promoção de programas sociais de moradia. A atuação do município, iniciada em 2006, foi bastante eficiente, com identificação das áreas não edificadas ou parceladas, especialmente aquelas maiores do que $50.000 \mathrm{~m}^{2}$. Contudo, o processo de notificação arrefeceu no ano de 2008, em razão de problemas decorrentes da desatualização ou imprecisão de dados cadastrais. Em 2009, com a substituição do Prefeito João Avamileno (PT) por Aidan Ravin (PTB), as medidas foram interrompidas. Uma dificuldade encontrada pelo município, que pode se constituir em um dos maiores desafios para os Poderes Legislativo e Executivo, é definir e aferir o critério de "não utilização" do imóvel. Os autores sugerem que se utilize como critério a verificação da utilização de serviços públicos de água, luz e coleta de lixo combinada com vistorias periódicas (BRUNO FILHO e DENALDI, 2009).

Uma das experiências mais longas de cobrança do IPTU progressivo no tempo foi a de Maringá, analisada por Brajato (2015). Entre 2009 e 2013 foram notificados cerca de 700 proprietários de imóveis não aproveitados, cuja área, somada, era de 14,5 milhões de metros quadrados (correspondente a $10 \%$ de toda a área urbana do município). Contudo, o município não tinha uma estratégia de ordenamento territorial para definição das áreas sujeitas à cobrança do imposto com função extrafiscal. Embora na primeira etapa tenham sido notificados proprietários de imóveis localizados nos anéis central e intermediário da cidade, com intenção de ampliar a oferta de habitação em locais com infraestrutura urbana, a ampliação aleatória da área de incidência do imposto, na segunda etapa, deu um viés exclusivamente fiscal à arrecadação. A conclusão de Brajato (2015, p. 211) é de que a experiência de Maringá favoreceu apenas "de forma limitada a ocupação dos vazios urbanos" e não contribuiu para combater a especulação imobiliária.

A falta de planejamento estratégico também prejudicou a utilização do instrumento em Palmas. Para a construção da cidade planejada, foram desapropriadas extensas glebas de terras, que acabaram não sendo ocupadas. Isso acarretou o desadensamento da cidade e 
favoreceu a especulação imobiliária, expulsando a população de baixa renda para as áreas periféricas. O município regulamentou a cobrança do imposto em 2009 e iniciou as notificações em 2013. Contudo, conforme estudo de Bazolli (2016), a atuação do Estado não foi direcionada aos maiores vazios urbanos e, dessa forma, não conseguiu interferir na supervalorização do mercado imobiliário. Da mesma forma como ocorreu em Maringá, priorizou-se a arrecadação tributária ao invés do planejamento urbano, de forma que, ao invés de contribuir para o acesso da população mais pobre à terra urbanizada, a cobrança do IPTU acabou levando à ocupação dos vazios com condomínios horizontais destinados à população de alta renda.

Essa constatação traz à baila questão levantada por Faria (2013): assim como os demais instrumentos urbanísticos, o IPTU progressivo no tempo pode ser utilizado para atender exclusivamente ao mercado, interessado na limpeza de determinadas áreas para viabilização de empreendimentos imobiliários. O autor cita o exemplo da regulamentação e aplicação do IPTU Progressivo em São Paulo na gestão do Prefeito Gilberto Kassab (PFL/DEM/PSD). Embora as medidas tivessem por objetivo declarado a desocupação de casas e apartamento abandonados para lhes dar função social, o conjunto de imóveis notificados (1.053) incluía 117 edifícios da região da "cracolândia" ${ }^{24}$. Interessante notar que a área da "cracolândia" foi inserida pela Prefeitura no perímetro da Operação Urbana Consorciada Centro, que reúne investimentos públicos e privados para revitalização da região central de São Paulo. Faria anota que os edifícios localizados nessa área - alguns deles antigos hotéis abandonados - foram apresentados pela imprensa como lugares que poderiam servir como residência após a revitalização da região. O curioso, segundo o autor, é que tais imóveis já serviam como moradia para inúmeras famílias que os ocupavam irregularmente e que, certamente, não seriam beneficiadas pela revitalização.

A experiência de Curitiba também é citada por Faria (2013) como um exemplo de desvirtuamento na utilização do IPTU progressivo no tempo. Nesse caso, o propósito da Prefeitura era declarado: remover os obstáculos à revitalização da região central - que abrigava imóveis transformados em "cortiços" - por meio da construção de um luxuoso centro comercial e turístico. O discurso sobre a função social da propriedade apareceu, nesse caso, apenas de forma tangencial: o município mencionava a possibilidade de atrair

\footnotetext{
${ }^{24}$ Trata-se de área no bairro de Santa Efigênia, centro de São Paulo, que passou a abrigar intenso tráfico de drogas a partir do final da década de 1990. Esse processo coincidiu com o processo de degradação do centro da cidade, com transferência do eixo comercial e de prestação de serviços para outras áreas da cidade.
} 
moradores para o centro da cidade a fim de estancar o decréscimo populacional dessa região. Contudo, o objetivo evidente era a remoção de ocupações irregulares para elitização da área central da cidade. Esse objetivo, anota Faria (2013, p.13), foi explicitado pelo próprio autor do projeto de lei que instituiu o tributo com alíquotas progressivas no tempo, segundo o qual a medida poderia contribuir para solucionar o problema de "invasões" de áreas ociosas.

A interferência política do mercado vai além da escolha das áreas sujeitas à cobrança de IPTU progressivo no tempo: atinge também os procedimentos para a cobrança do tributo, tais como a adequação das Plantas Genéricas de Valores dos imóveis aos preços de mercado, atualização de dados cadastrais dos contribuintes, notificações dos proprietários de imóveis ociosos etc. O município de São Paulo retomou a utilização do IPTU com função extrafiscal na gestão do Prefeito Fernando Haddad, por meio da edição do decreto 56.589/2015, que dava aos proprietários de imóveis subaproveitados o prazo de um ano para promover uso adequado de seus terrenos e edificações, sob pena de cobrança progressiva do IPTU. Foram notificados, à época, 1.073 proprietários de imóveis ociosos. Contudo, a alternância partidária na Prefeitura, com a vitória da chapa João Dória/Bruno Covas (PSDB), em 2016, levou à redução expressiva do número de servidores públicos no órgão municipal encarregado das notificações e queda brusca desses procedimentos, que foram praticamente abandonados em 2018 (AMÂNCIO, 2019).

As experiências pesquisadas revelam que a utilização do IPTU progressivo com função extrafiscal não é uma tarefa fácil. Além da necessidade de cadastramento eficiente dos valores dos imóveis e dos dados dos proprietários, é preciso estabelecer critérios adequados para identificar e aferir os imóveis que não estão cumprindo a sua função social. É essencial, ainda, estabelecer uma estratégia de ocupação do solo que viabilize a cobrança do imposto em áreas nas quais o Estado pretenda promover o adensamento populacional. Além disso, a utilização do IPTU com função extrafiscal para requalificação urbana deve priorizar o interesse social, representado pela garantia do direito à moradia. Não se pode perder de vista que o IPTU progressivo no tempo é um instrumento de política urbana, de sorte que sua cobrança deve ter por objetivo orientar o crescimento e desenvolvimento urbano de acordo com os interesses da coletividade, o que implica em tornar o mercado imobiliário mais acessível à população de baixa renda.

\section{CONCLUSÃO}


$\mathrm{O}$ artigo demonstrou que, embora o IPTU apresente diversas vantagens sobre os demais impostos (pouca oscilação arrecadatória, arrecadação não sujeita à guerra fiscal, facilidade dos procedimentos de cobrança), sua arrecadação pelos municípios está aquém da arrecadação de países que têm alíquotas semelhantes às do Brasil. Tal circunstância pode ser explicada pela ocorrência de problemas operacionais, tais como falta de atualização das bases de cadastro, ineficiência na fixação das alíquotas, excesso de isenções; mas também pela existência de um mercado informal de imóveis não cadastrados pelos órgãos do governo.

Mostrou-se, ainda, que o IPTU com função extrafiscal, previsto no artigo $182, \S 4^{\circ}$, inciso II, da Constituição Federal, vem sendo subutilizado pelos municípios. Considerando-se que o mercado imobiliário brasileiro é altamente especulativo, a instituição de alíquotas progressivas na cobrança do IPTU para induzir o adequado aproveitamento dos imóveis urbanos pode contribuir para a solução de problemas gerados pelo crescimento disfuncional das cidades, tais como retenção de imóveis ociosos, produção de vazios urbanos e degradação de áreas centrais das grandes cidades em razão da migração de atividades comerciais, de serviços e residenciais para novas centralidades

A pesquisa de trabalhos acadêmicos sobre experiências de implantação do IPTU progressivo no tempo em municípios brasileiros revelou que o mercado exerce pressão política sobre a Administração Pública com o objetivo de: (i) apropriar-se do instrumento jurídico-urbanístico para atendimento de interesses exclusivos do capital, como, por exemplo, a desocupação de áreas visadas para empreendimentos imobiliários; (ii) bloquear a eficácia das normas que instituem a cobrança do IPTU com função extrafiscal, por meio de empecilhos burocráticos, tais como: falta de adequação das Plantas Genéricas de Valores dos imóveis cadastrados no município aos preços do mercado, desatualização do cadastro dos proprietários, diminuição e paralisação das notificações etc.

Além de evitar a pressão política do mercado, outro desafio para os municípios é definir e aferir o critério a ser utilizado para classificar um imóvel como não utilizado adequadamente. É essencial para o êxito da utilização do IPTU progressivo no tempo que as prefeituras compreendam que esse é um instrumento de intervenção urbanística, e não de mera arrecadação fiscal. Nesse sentido, a escolha das áreas onde incidirá o imposto é fundamental para combater os vazios urbano; evitar a especulação imobiliária e consequente supervalorização do preço dos imóveis; e promover o aproveitamento dos imóveis vagos, com aumento da oferta habitacional. 


\section{REFERÊNCIAS BIBLIOGRÁFICAS}

ADAMY, Pedro. Origens Teóricas da Extrafiscalidade. Revista Direito Tributário Atual, São Paulo: Dialética, n. 39, p. 367-376, 2018.

AMÂNCIO, Thiago. Doria e Covas abandonam caça a imóvel vazio ou subutilizado em SP.

Folha de São Paulo, São Paulo, 22 jan. 2019. Disponível em: <

https://www1.folha.uol.com.br/cotidiano/2019/01/doria-e-covas-abandonam-caca-a-imovelvazio-ou-subutilizado-em-sp.shtml >. Acesso em 09 fev. 2019.

BALEEIRO. Aliomar. Uma Introdução à Ciência das Finanças, Forense, Rio de Janeiro, 2001.

BAZOLLI, João Aparecido. Parcelamento, Edificação e Utilização Compulsórios (PEUC): avaliação e resultados da aplicação em Palmas - TO. Revista de Direito da Cidade, vol. 08, $\mathrm{n}^{\circ}$ 4, p. 1.254-1.276, 2016.

BRAJATO, Dânia. A Efetividade dos Instrumentos do Estatuto da Cidade: o caso da aplicação do parcelamento, edificação ou utilização compulsórios no município de Maringá (PR). 2015. 221 fl. Dissertação (Planejamento e Gestão do Território). Universidade Federal do ABC, Santo André, 2015. Disponível em: <http://lepur.com.br/wpcontent/uploads/2017/12/09-Disserta\%C3\%A7\%C3\%A3o-D\%C3\%A2nia-Brajato.pdf >. Acesso em 08 fev. 2019.

BRASIL. MINISTÉRIO DA JUSTIÇA. SECRETARIA DE ASSUNTOS LEGISLATIVOS. Parcelamento, Edificação ou Utilização Compulsórios e IPTU Progressivo no Tempo: Regulamentação e Aplicação. Caderno Pensando o Direito n. 56. Brasília: Ministério da Justiça, Secretaria de Assuntos Legislativos (SAL)/Ipea: 2015a. Disponível em: < http://pensando.mj.gov.br/wp-content/uploads/2015/11/PoD_56_web1.pdf >. Acesso em 08 fev. 2019.

BRASIL. MINISTÉRIO DAS CIDADES. SECRETARIA NACIONAL DE ACESSIBIILDADE E PROGRAMAS URBANOS. Parcelamento, Edificação ou Utilização Compulsórios e IPTU Progressivo no Tempo: Caderno Técnico de Regulamentação e Implementação. Brasília: Ministério das Cidades, 2015b. Disponível em: < http://www.caubr.gov.br/wp-content/uploads/2017/10/CAPACIDADES2.pdf >. Acesso em 08 fev. 2019.

BRITO, Fausto. O deslocamento da população brasileira para as metrópoles. Estudos Avançados, São Paulo, v. 20, n. 57, ago. 2006. Disponível em: 
<http://www.scielo.br/scielo.php?pid=S0103-40142006000200017\&script=sci_arttext.>

Acesso em: 08 nov. 2013.

BRUNO FILHO, Fernando Guilherme; DENALDI, Rosana. Parcelamento, Edificação e Utilização compulsórios: um instrumento (ainda) em construção. Revista Pós, São Paulo, v.16, n. 26, p. 34-49, dez. 2009.

CARDOSO, Adauto Lúcio. Avanços e desafios na experiência brasileira de urbanização de favelas. Cadernos Metrópole, n. 17, p. 219-240, $1^{\text {o }}$ sem. 2007. Disponível em: < http://www.urbanismo.mppr.mp.br/arquivos/File/CARDOSO Avancosedesafiosnaxperiencia brasileiradeurbanizacaoeavelas.pdf>. Acesso em 08 fev. 2019.

. Vazios Imobiliários. In: FERREIRA, Regina Fátima C. F.; BIASOTTO, Rosane

Coreixas. Políticas Públicas e Direito à Cidade: política habitacional e o direito à moradia digna. Rio de Janeiro: Letra Capital, 2012.

CARVALHO JÚNIOR, Pedro Humberto Bruno. Aspectos Distributivos do IPTU e do Patrimônio Imobiliário das Famílias Brasileiras. Instituto de Pesquisa Econômica Aplicada (IPEA), Texto para discussão 1417. Brasília: Livraria IPEA, ago. 2009.

- Imposto predial e territorial urbano - IPTU. Associação Nacional dos Auditores-

Fiscais da Receita Federal do Brasil e da Federação Nacional do Fisco Estadual e Distrital, Cadernos de Reforma Tributária n. 5, dez. 2017.

COSTA, Marco Aurélio; GOMES, Ana Maria Isar dos Santos; ADRIANO, Henrique Soares Rabelo. Política nacional de desenvolvimento urbano: ambivalências, tensões e contradições. In STEIBERGER, Marília (org.). Território, agentes-atores e política públicas espaciais. Brasília: Ler Editora, 2017.

CRUZ, João Carlos Lima. O IPTU Progressivo e sua Função Social: análise da implantação desse instrumento na cidade de Palmas (TO). 2017. 132 fl. Dissertação (Economia, Planejamento e Desenvolvimento Regional). Universidade Federal do Tocantins, Palmas, 2017. Disponível em: < http://repositorio.uft.edu.br/handle/11612/598 >. Acesso em 09 fev. 2019.

ELGOT, Jessica. Jeremy Corbyn urges PM to rethink terms of Grenfell fire inquiry. The Guardian (on-line), UK edition, 17 aug. 2017. Disponível em: < https://www.theguardian.com/uk-news/2017/aug/17/jeremy-corbyn-theresa-may-lettergrenfell-tower-fire-inquiry >. Acesso em: 01 abr. 2019. 
FARIA, José Ricardo Vargas de. Função Social e IPTU Progressivo: o avesso do avesso num desenho lógico. In: XV Encontro Nacional da ANPUR, 2013, Recife. Anais... vol. 15. Rio de Janeiro: ANPUR, 2013.

FIX, Mariana. Cidade Global: fundamentos financeiros de uma miragem. São Paulo: Editora Boitempo, 2007.

FLOETER, Roberto de Almeida. A Eficácia do IPTU Progressivo como Instrumento de Planejamento Urbano: A Experiência do Município de Assis, SP. 2007. 126 f. Dissertação (Engenharia Urbana). Centro de Ciências Exatas e de Tecnologia. Universidade Federal de São Carlos, São Carlos, 2007. Disponível em: < https://repositorio.ufscar.br/bitstream/handle/ufscar/4250/2175.pdf?sequence=1 >. Acesso em 08 fev. 2019.

FUNDAÇÃO JOÃO PINHEIRO, Diretoria de Estatística e Informações. Déficit habitacional no Brasil 2015. Belo Horizonte: FJP, 2018. Disponível em: <http://www.fjp.mg.gov.br/index.php/docman/direi-2018/estatistica-e-informacoes/7976-serie-estatistica-e-informacoes-deficit-habitacional-no-brasil-2015/file>. Acesso em 08 fev. 2019

GODOI, Marciano Seabra de. Finanças Públicas Brasileiras: diagnóstico e combate dos principais entraves à igualdade social e ao desenvolvimento econômico. Rio de Janeiro, Revista de Finanças Públicas, Tributação e Desenvolvimento, v. 5, n.5, 2017.

LISBÔA, Gabriela. Centro de São Paulo tem pelo menos outros 70 prédios ocupados. Site de notícias R7, São Paulo, 01 mai. 2018. Disponível em: <https://noticias.r7.com/saopaulo/centro-de-sao-paulo-tem-pelo-menos-outros-70-predios-ocupados-02052018>. Acesso em 08 fev. 2019.

LONDON boroughs join forces to alleviate homelessness crisis. The Guardian (on-line), UK edition, 31 dez. 2018. Disponível em:

https://www.theguardian.com/society/2018/dec/31/london-boroughs-join-forces-to-alleviatehomelessness-crisis >. Acesso em 01 abr. 2019.

MACHADO, Hugo de Brito. Curso de Direito Tributário. 26ª ed. São Paulo: Malheiros, 2005. MARGUTI, Bárbara Oliveira. Políticas de Habitação. In: COSTA, MAGALHÃES e FAVARÃO (org.). A nova agenda urbana e o Brasil : insumos para sua construção e desafios a sua implementação. Brasília: Ipea, 2018.

MARICATO, Ermínia. O impasse da política urbana no Brasil. Petrópolis: Vozes, 2011. 
MARINS, James; TEODOROVICZ, Jeferson. Rumo à Extrafiscalidade Socioambiental: tributação diante do desafio social e ambiental contemporâneo. In: IX Simpósio Nacional de Direito Constitucional da Academia Brasileira de Direito Constitucional, Curitiba, 2010. Anais ... Curitiba: Academia Brasileira de Direito Constitucional, 2011.

MOREIRA, Vinicius de Souza; SILVEIRA, Suely de Fátima Ramos; EUCLYDES, Fillipe Maciel. "Minha Casa, Minha Vida" em Números: quais conclusões podemos extrair? In: IV Encontro Brasileiro de Administração Pública, João Pessoa, mai. 2017. Disponível em: < http://www.ufpb.br/ebap/contents/documentos/0594-613-minha-casa.pdf >. Acesso em 07 fev. 2019.

OLIVEIRA, Fabricio Leal; BIASOTTO, Rosane. O Acesso à Terra Urbanizada nos Planos Diretores Brasileiros. In: JUNIOR, Orlando Alves dos Santos; MONTANDON, Daniel Todtmann (orgs.). Os Planos Diretores Municipais Pós-Estatuto da Cidade: balanço crítico e perspectivas. Rio de Janeiro: Letra Capital; Observatório das Cidades; IPPUR/UFRJ, 2011. QUIERATI, Luciana. Prédio desaba no centro de São Paulo após incêndio. UOL, São Paulo, 29 set. 2018. Disponível em: < https://noticias.uol.com.br/cotidiano/ultimasnoticias/2018/09/29/predio-desaba-no-centro-de-sao-paulo-apos-incendio.htm ROLNIK, Raquel. Guerra Dos Lugares: a colonização da terra e da moradia na era das finanças. São Paulo: Boitempo Editorial, 2015.

ROLNIK, Raquel; KLINK, Jeroen. Crescimento econômico e desenvolvimento urbano: por que nossas cidades continuam tão precárias ? Revista Novos Estudos, n. 89, p. 109, mar. 2011.

SMITH, Adam. A Riqueza das Nações: investigações sobre sua natureza e sua causa. Vol. 2. Tradução de Luiz João Baraúna. São Paulo, Editora Nova Cultural Ltda., 1996.

SMOLKA, Martim. Informality, Urban Poverty and Land Market Prices. Revista Land Lines, Lincoln Institute of Land Policies, edição digital, jan. 2003. Disponível em: https://www.lincolninst.edu/pt-br/publication s/articles/informality-urban-poverty-landmarket-prices>. Acesso em 08 fev. 2019.

TORRES, Ricardo Lobo. Curso de Direito Financeiro e Tributário.13 ${ }^{\mathrm{a}}$ ed. Rio de Janeiro: Renovar, 2006.

UNITED KINGDOM GOVERNMENT. MINISTRY OF HOUSING, COMMUNITIES AND LOCAL GOVERNMENT. Council Tax: empty homes premium. Disponível em: < https://www.gov.uk/government/publications/council-tax-empty-homes-premium >. Acesso em: 01 abr. 2019. 
UNITED KINGDOM. THE ROYAL BOROUGH OF KENSINGTON AND CHELSEA.

Council tax empty properties. Disponível em: < https://www.rbkc.gov.uk/council-tax/council-

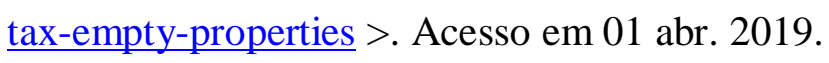

WALKER, Peter; PEGG, David. Huge number of empty homes near Grenfell 'simply unacceptable'. The Guardian (on-line), UK edition, 2 aug. 2017. Disponível em:

<https://www.theguardian.com/uk-news/2017/aug/02/revelations-about-empty-homes-ingrenfell-area-simply-unacceptable >. Acesso em: 01 abr. 2019. 